Original Research Article

\title{
Pattern of management of febrile neutropenia among breast cancer patients treated with different chemotherapeutic regimens
}

\author{
Arun S., Seema P. Mohamedali*, Anuradha M.
}

Department of Pharmacology, Govt. Medical College, Kozhikode, Kerala India

Received: 16 July 2018 Accepted: 11 August 2018

\section{*Correspondence to:} Dr. Seema P. Mohamedali, Email: seemapharmac@ gmail.com

Copyright: (c) the author(s), publisher and licensee Medip Academy. This is an openaccess article distributed under the terms of the Creative Commons Attribution NonCommercial License, which permits unrestricted noncommercial use, distribution, and reproduction in any medium, provided the original work is properly cited.

\begin{abstract}
Background: Breast cancer is one of the common malignancies in females. Chemotherapy with Adriamycin and Cyclophosphamide (AC) followed by the Docetaxel (AC-T, Regimen-I), AC followed by Docetaxel and Carboplatin (AC$\mathrm{T}+\mathrm{Cr}$, Regimen-II) and AC followed by Docetaxel and Trastuzumab (AC-T+Tr, Regimen-III) are commonly given for treatment. These cause myelosuppression and febrile neutropenia and need necessary interventions.

Methods: This is a prospective open labelled observational comparative study to evaluate the antibiotic usage needed to treat sepsis following febrile neutropenia among breast cancer patients undergoing chemotherapy with regimen I, II and III. All patients received prophylactic Pegfilgrastim / Filgrastim. Antibiotics used and days in intensive care unit (ICU) in all the 8 cycles of chemotherapy were recorded. 38 patients in Regimen I, 40 patients in Regimen II and 46 patients in Regimen III completed the study and were included in the statistical analysis.

Results: In regimen II, following cycle 2 of chemotherapy, none of the patients needed antibiotic therapy. Antibiotic use was maximum, following cycle 1 of chemotherapy in regimen I and III, maximum number of antibiotics prescribed were 7. Number of days of ICU care needed for regimen II patients following 3rd cycle of chemotherapy was $3.5 \pm 3.5$ days. No ICU care was needed for regimen III patients, following cycles 2, 3 and for regimen II following cycle 7.

Conclusions: Febrile neutropenia produced by chemotherapy were effectively treated with intravenous antibiotics in ICU for an average of 2-3 days. No mortality was associated with febrile neutropenia and all patients were recovered.
\end{abstract}

Keywords: Antibiotic usage, Breast cancer, Chemotherapeutic regimens, Febrile neutropenia, ICU care

\section{INTRODUCTION}

Breast cancer is one of the common malignancies in female's worldwide. ${ }^{1}$ It is a heterogenous disease caused by many factors like progressive accumulation of genetic aberrations, including point mutations, chromosomal amplifications, deletions, rearrangement and translocations. ${ }^{2}$ One of the most important risk factor of breast cancer is family history. Therapeutic efficacy and better survival depend on the early detection and treatment with right chemotherapeutic regimens according to the stage and histopathology. Breast cancer treatment consists of multimodality that are of surgery, chemotherapy, radiation therapy and biological therapy. ${ }^{3}$ Anthracycline based chemotherapeutic regimens are being commonly used. ${ }^{4}$ Three common regimens used for the therapeutic purpose in breast cancer are Adriamycin based. Adriamycin and Cyclophosphamide (AC) followed by Docetaxel (AC-T, Regimen-I), AC followed by Docetaxel and Carboplatin (AC-T+Cr, Regimen-II) and AC followed by Docetaxel and Trastuzumab (AC-T+Tr, Regimen III) are usually given to patients with stage 0 to stage 3 disease. ${ }^{4}$ As with any chemotherapeutic regimens, breast cancer chemotherapy especially the above mentioned anthracycline and taxanes cause myelosuppression leading to febrile neutropenia that need necessary interventions. ${ }^{5}$ Better therapeutic outcomes with reduced morbidity and mortality to treat febrile neutropenia and ways to prevent 
it is the need of the hour. Febrile neutropenia is the dose limiting adverse effect of cancer chemotherapy which may lead to life threatening infections which needs treatment with parenteral antibiotics. ${ }^{6}$ Risk of infection and mortality increases with the duration and severity of neutropenia and patient related factors. Prophylactic use of Granulocyte colony stimulating factor (G-CSF) significantly reduces the incidence of febrile neutropenia and the need of antibiotic usage, thereby reducing the number of days of hospitalisation. ${ }^{6}$ Common guidelines recommends the use of bone marrow stimulating agents as Pegfilgrastim or Filgrastim (G-CSF) with chemotherapeutic regimens that are associated with an incidence of febrile neutropenia $\geq 20 \%{ }^{7}$ Drugs associated with low risk of febrile neutropenia are CMF (Cyclophosphamide, Methotrexate, 5-Flurouracil), and FAC (5-Flurouracil, Doxorubicin, Cyclophosphamide). ${ }^{8}$ A phase 3 placebo controlled double blind randomised trial of Pegfilgrastim in patients with breast cancer who received Docetaxel in Europe and North America demonstrated that it significantly reduces the incidences of febrile neutropenia, febrile neutropenia related hospitalisation, and use of antibiotics. ${ }^{9}$ Overall aim of G-CSF support is to reduce the incidence of chemotherapy induced neutropenia. Current study was planned to make an assessment of various antibiotics used, number of antibiotics used and duration of stay in the ICU as a part of treatment for established cases of febrile neutropenia.

\section{Treatment of febrile neutropenia in intensive care unit}

\section{Antibiotic therapy}

The common antimicrobials or combinations used are Piperacillin -Tazobactum combination used as monotherapy. 4.5 gram $6^{\text {th }}$ hourly in microbial spectrum of enterobacteriacea, pseudomonas aeruginosa, most gram positive bacteria excluding Methicillin Resistant Staphylococcus Aureus (MRSA) and anaerobes. Carbapenems (Imipenem, Meropenem, Ertapenem) given for same spectrum of organisms that of Piperacillin and doses are Imipenem as 500mg 6th hourly, Meropenem 1$2 \mathrm{~g} 8^{\text {th }}$ hourly, Ertapenem $1 \mathrm{gm}$ per day. Vancomycin $1 \mathrm{gm}$ $12^{\text {th }}$ hourly for gram positive bacteria, Linezolid $600 \mathrm{mg}$ $12^{\text {th }}$ hourly for gram positive bacteria including MRSA and Vancomycin Resistant Enterococci (VRE). Metronidazole $500 \mathrm{mg} 6^{\text {th }}$ hourly exclusively for anaerobic infections as per microbial culture and sensitivity. Aminoglycosides, fluroquinolones, Cefepime and Ceftazidime are also be used according to local culture and sensitivity. ${ }^{10}$

\section{METHODS}

This study was conducted to evaluate the antibiotic usage needed to treat sepsis following febrile neutropenia in breast cancer patients undergoing chemotherapy with different regimens like regimen I, II and III. All patients both inpatients and outpatients were administered the chemotherapeutic regimens under Pegfilgrastim/ Filgrastim support prophylatically, as a standard protocol to reduce the incidence of febrile neutropenia in oncology department in a tertiary care centre. The antibiotics prescribed, number of antibiotics prescribed, their dosage and number of days of ICU care for chemotherapy induced febrile neutropenia during all the 8 cycles of chemotherapy were recorded in a structured proforma.

It was prospective open labelled observational comparative study. The study was done after getting clearance from institutional ethics committee.The study was conducted over a period of 1 year from January 2016 to December 2016. There were 41 Patients in each group.

\section{Calculated by formula}

$\mathrm{N}=2 \mathrm{pq}(\text { Zcrit }+\mathrm{Zpwr})^{2} / \mathrm{D}^{2}$.

\section{Inclusion criteria}

- Patients with Normal cognition

- Paients with breast malignancy of age group 18- 65 year and Stages 1 to 3

- With G-CSF support (Pegfilgrastrim / Filgrastrim)

- Absolute neutrophil count $>1.5 \times 10^{9} / 1$

- $\quad$ Platelet count $>100 \times 10^{9} / 1$

- Serum creatinine $<2$

- Serum total bilirubin <1.5 times the upper limit of normal.

\section{Exclusion criteria}

- $\quad$ Stage 4 metastatic patients

- Concurrent other malignancies

- Cardiac failure, Myocardial infarction in past 1 year

- Pregnancy and Nursing population

- Prior bone marrow transplantation or stem cell therapy

Written informed consent was taken from all the study subjects before starting the study in vernacular language.

\section{Study procedure}

After screening the patients who fulfil the inclusion criteria were enrolled in the study. Patients were enrolled into three groups, patients undergoing chemotherapy with regimen I, regimen II and regimen III. Regimen I included those patients receiving AC followed by Docetaxel. Regimen II included those patients with AC followed by Docetaxel and Carboplatin. Regimen III included AC followed by Docetaxel and Trastuzumab. After screening, 132 patients who satisfy the inclusion criteria were included in the study. The first group with 42 patients received regimen I, second group with 42 patients received regimen II, third group with 48 patients received regimen III. 4 patients in Regimen I, 2 each from Regimen II and Regimen III were dropped out from the study, hence 38 patients in Regimen I, 40 patients in Regimen II and 46 
patients in Regimen III were included for the statistical analysis.

\section{Dosage and administration}

\section{AC-docetaxel regimen ${ }^{11}$}

Doxorubicin $60 \mathrm{mg} / \mathrm{m}^{2}$ and Cyclophosphamide $600 \mathrm{mg} / \mathrm{m}^{2}$ every 3 weeks for four cycles followed by the Docetaxel $100 \mathrm{mg} / \mathrm{m}^{2}$ every 3 weeks for four cycles.

\section{AC-docetaxel and carboplatin regimen ${ }^{12,13}$}

$\mathrm{AC}$ regimen for four cycles (Doxorubicin $60 \mathrm{mg} / \mathrm{m}^{2}$ and Cyclophosphamide $600 \mathrm{mg} / \mathrm{m}^{2}$ every 3 weeks). Carboplatin and Docetaxel for next four cycles. Carboplatin dose: AUC of 6 intravenously on day 1. Docetaxel: $75 \mathrm{mg} / \mathrm{m}^{2}$ intravenously on day 1 . Repeat in every 21 days for four cycles.

\section{AC-docetaxel and trastuzumab regimen ${ }^{11}$}

AC regimen for four cycles followed by the Docetaxel and Trastuzumab given for 2 cycles. Docetaxel dose: $75 \mathrm{mg} / \mathrm{m}^{2}$ intravenously on day 1 and Trastuzumab $4 \mathrm{mg} / \mathrm{kg}$ intravenously loading dose and then $2 \mathrm{mg} / \mathrm{kg}$ intravenously weekly. Repeat chemotherapy every 21 days for a total 6 cycles.

Dosage of Pegfilgrastim / Filgrastim for neutropenia associated with myelosuppressive Chemotherapy

$5 \mathrm{mcg} / \mathrm{kg} /$ day subcutaneous administration is preferred over intravenous route until absolute neutrophil count is 2$3 \times 10^{9} / \mathrm{mcl}$ or for up to 14 days. Pegylated Filgrastrim is administered 6mg subcutaneously once per chemotherapy cycle. Do not administer within 24 hours of administration of chemotherapy or within 14 days before administration of chemotherapy. ${ }^{14}$

\section{Outcome assessment}

Established number of cases of febrile neutropenia, the antibiotic therapy used, number of antimicrobials used to suppress one episode and number of days of intensive care treatment were recorded in each cycles of chemotherapy during the treatment period and followed up to 8 cycles completely.

\section{Statistical analysis}

Statistical analysis was done using Statistical Package for Social Science (SPSS) software version 22.

\section{RESULTS}

Mean age of overall study population was $49.2 \pm 8.6$ years. In patients receiving Regimen I, 7.9\% were in stage-I breast cancer, $52.6 \%$ in stage- 2 and $39.5 \%$ in stage- 3 . In patients receiving Regimen II, 5\% were in stage-I, 50\% in stage-2, $45 \%$ in stage- 3 . In patients receiving Regimen III $4.3 \%$ in stage-I, $41.3 \%$ in stage- $2,54.3 \%$ in stage- 3 with a chi-square value 2.17 and $p$ value 0.705 . All the three groups were comparable in baseline characteristics.

Out of total 61 episodes of febrile neutropenia which occurred in all cycles of chemotherapy, 41 episodes were of grade $3(67 \%), 20$ episodes were of grade $4(33 \%)$ neutropenia. Occurrence of Grade 4 neutropenia was more with regimen II with a total of 9 episodes (14.7\%) and least with regimen III with 5 episodes $(8.1 \%)$ and 6 episodes $(9.8 \%)$ with regimen I. All patients received prophylaxis with pegfilgrastim alone or in combination with filgrastim. $73(59 \%)$ patients received pegfilgrastim alone and 51 (41\%) patients received a combination of pegfilgrastim and filgrastim as prophylaxis. Dose reduction and delay in starting the next cycle of chemotherapy due to febrile neutropenia was reported in only one patient in regimen II. No death was reported during the study period due to febrile neutropenia.

\section{Pattern of antibiotic usage in established cases of febrile neutropenia}

In cycle 1, Piptaz (Piperacillin-Tazobactum), Ciplox (Ciprofloxacin), Moxclav (Amoxicillin-Clavulanic acid) and their combinations are given for treatment. They are represented as the percentage of usage among the patients receiving three regimens. Moxclav was the most commonly used antibiotic among all. Moxclav was given in $57 \%$ of patients in regimen I, $40 \%$ in regimen II. $40 \%$ of patients in regimen II received Piptaz+Ciplox. $43 \%$ in regimen III received Ciplox (Figure 1).

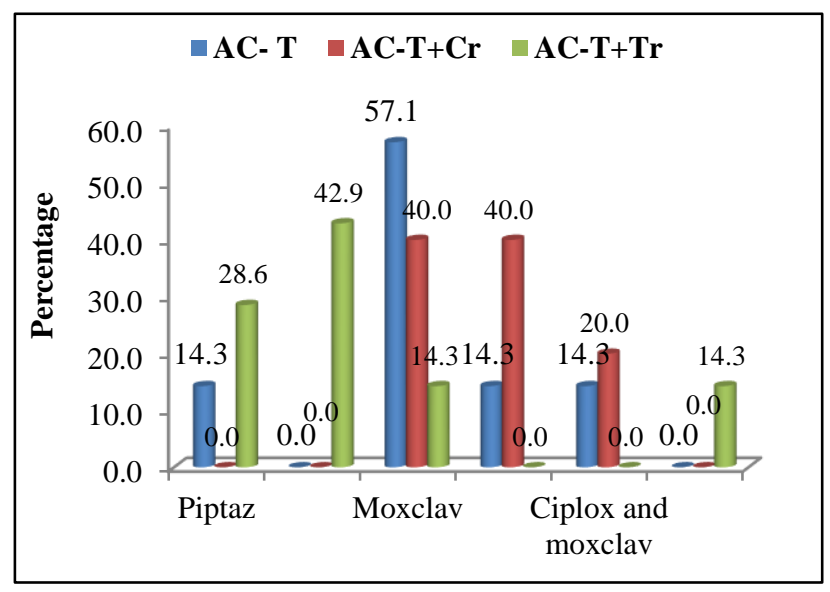

\section{Figure 1: Distribution of antibiotics for treatment of established case of febrile neutropenia among 3 regimens in cycle 1 .}

In cycle 2 Moxclav was the most used antibiotic and Ciplox was the least used one. Combination of Piptaz, Ciplox and Moxclav was prescribed for regimen II. No antibiotics were needed by patients in regimen III (Figure 2). 


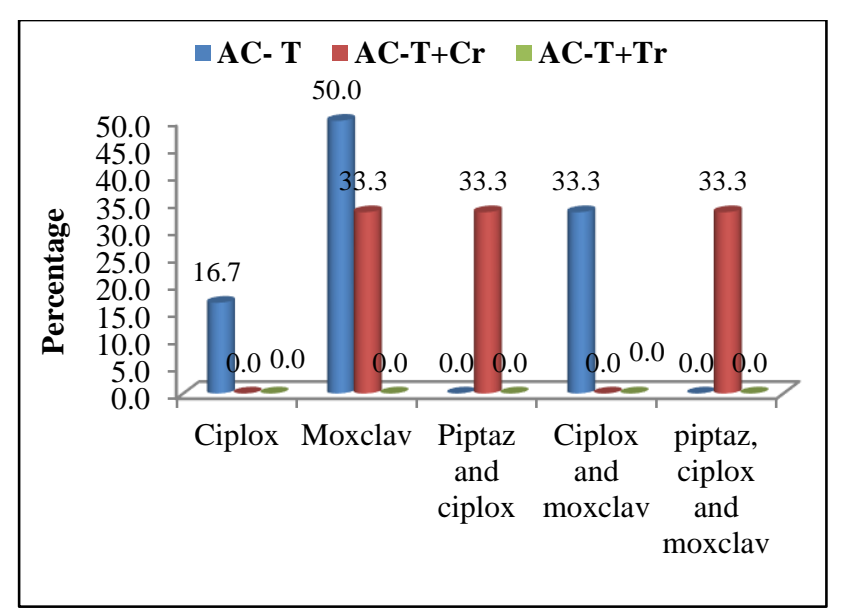

Figure 2: Distribution of antibiotics for treatment in established case of febrile neutropenia in 3 regimens in cycle 2 .

In cycle 3 , all the patients $(100 \%)$ in regimen III received Ciplox. $50 \%$ of patients in regimen I, received Moxclav and $50 \%$ received Piptaz+Ciplox. 50\% of the patients in regimen II, received Moxclav, 25\% received Piptaz+Ciplox and 25\% Piptaz+Moxclav (Figure 3).

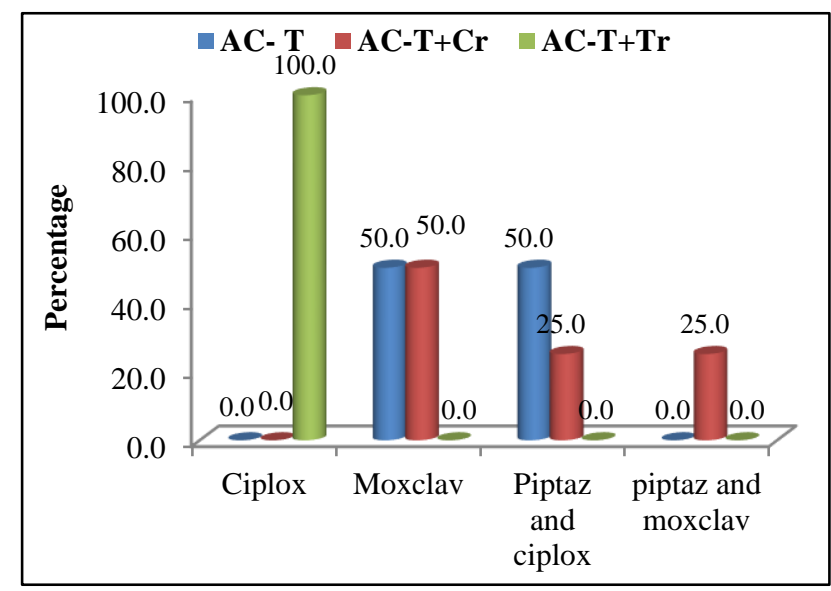

Figure 3: Distribution of antibiotic and combination for treatment in established cases of febrile neutropenia in 3 regimens in cycle 3 .

In cycle 4, 100\% patients in regimen II received Moxclav, $100 \%$ patients in regimen III received Piptaz (Figure 4).

In cycle 5, 50\% patients in regimen I received Piptaz+Moxclav. $50 \%$ of patients in regimen II received Piptaz+Ciplox \& 50\% received Moxclav+Meropenem. In regimen III febrile neutropenia was treated with Piptaz, Ciplox, Moxclav and Ciplox+Moxclav (Figure 5).

In cycle 6 , in regimen I, 25\% patients received Piptaz, Ciplox, Ciplox+Moxclav, Piptaz+Moxclav respectively. In regimen II, 67\% received Moxclav and 33\% received Piptaz. In regimen III 33\% received Piptaz, Piptaz+Ciplox and Piptaz+Ciplox+Moxclav+Others respectively (Figure $6)$.

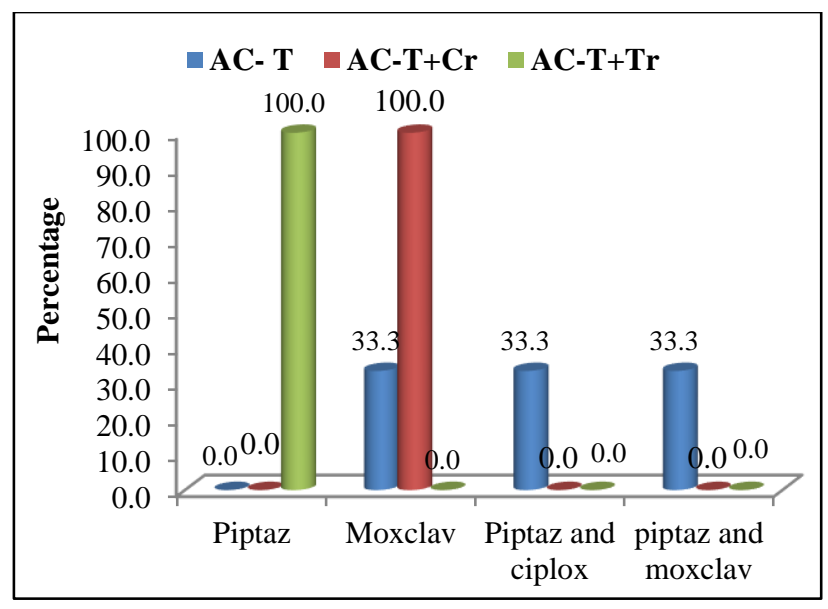

Figure 4: Distribution of antibiotic and combination for treatment in established cases of febrile neutropenia in 3 regimens in cycle 4.

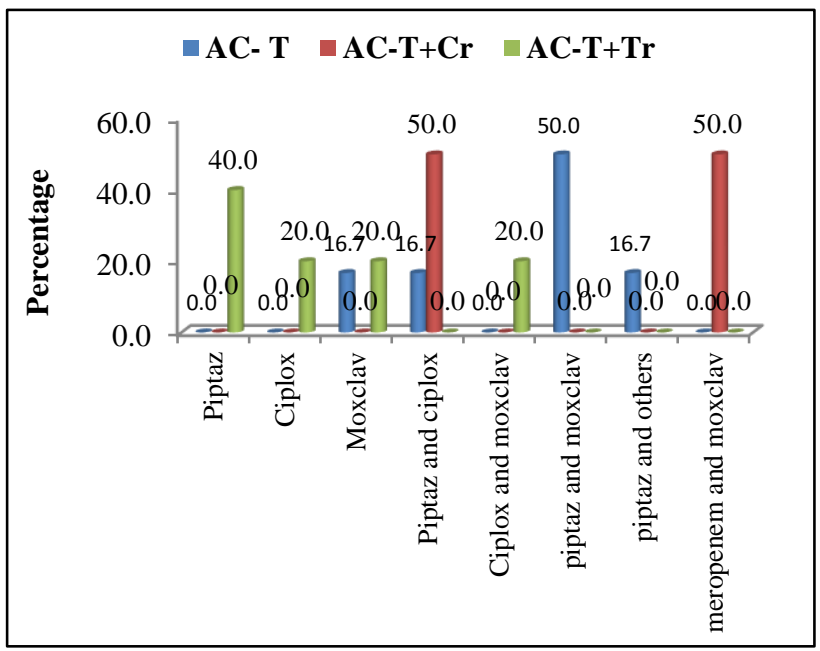

Figure 5: Distribution of antibiotics for treatment of established cases of febrile neutropenia in 3 regimens in cycle 5.

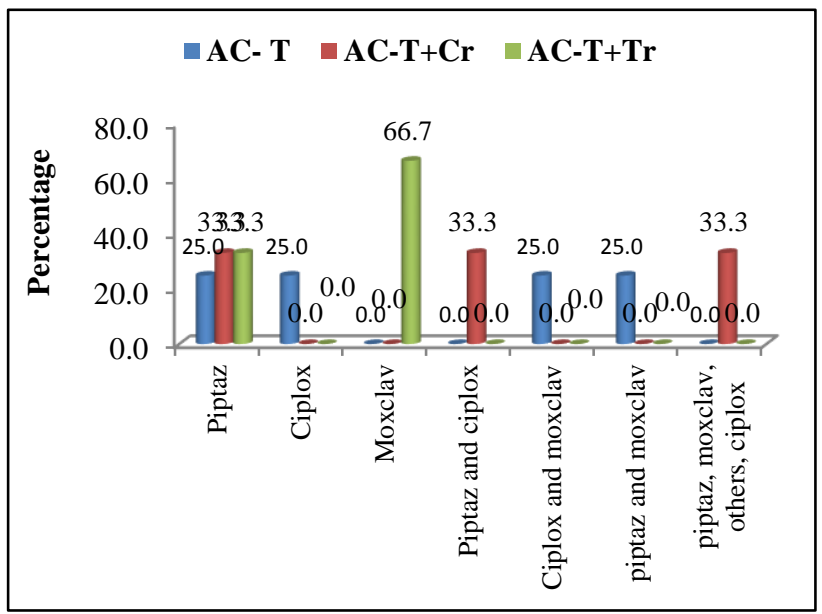

Figure 6: Distribution of antibiotics for treatment of established cases of febrile neutropenia in 3 regimens in cycle 6. 
In cycle 7 , in regimen I, $100 \%$ patients received Piptaz. Regimen II, 100\% patients received Moxclav. Regimen III $50 \%$ with Ciplox+Moxclav and 50\% with Piptaz+Moxclav (Figure 7).

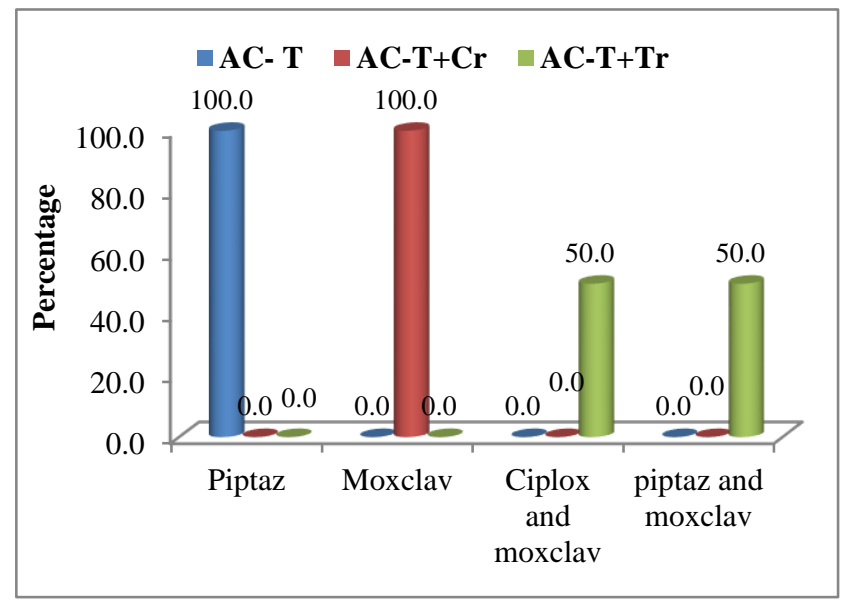

Figure 7: Distribution of antibiotics for treatment of established cases of febrile neutropenia in 3 regimens in cycle 7.

In cycle $8,50 \%$ patients in regimen I with Piptaz and 50\% with Piptaz+Cefixime. Regimen II, $100 \%$ with Moxclav. Regimen III 50\% with Cefixime and $50 \%$ with Ciplox+Moxclav (Figure 8).

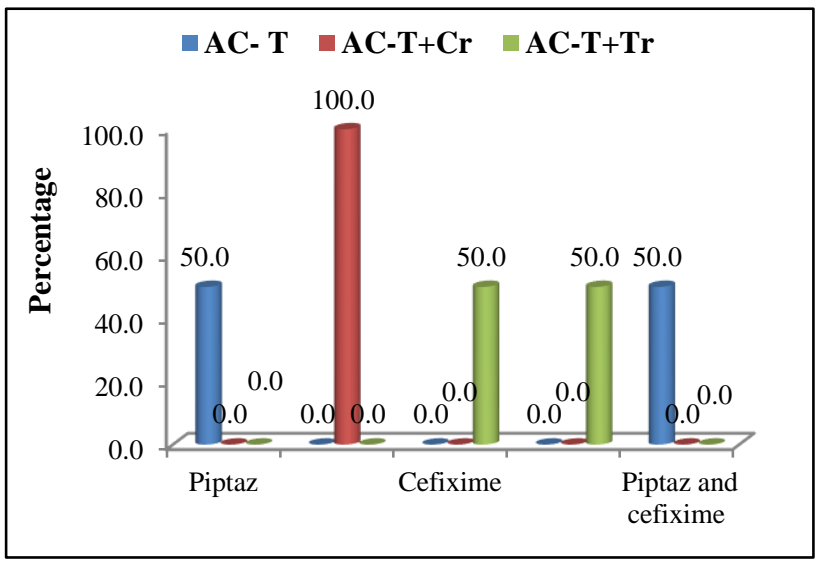

Figure 8: Distribution of antibiotics for treatment of established cases of febrile neutropenia in 3 regimens in cycle 8.

Number of different types of antibiotics prescribed for all the three regimens in all cycles of chemotherapy are given in Table 1.

During chemotherapy cycle 2 in regimen II, no antibiotics were needed for any of the patient. Maximum number of antibiotics used to treat one episode of febrile neutropenia was 7 and was used during cycle 1 in regimen I and III.

Intensive care unit treatment required for febrile neutropenia and number of days of ICU care (Table 2).
Table 1: Number of antibiotics prescribed in three regimens in all cycles of chemotherapy.

\begin{tabular}{|lllll|}
\hline $\begin{array}{l}\text { No of Cycles of } \\
\text { Chemotherapy }\end{array}$ & AC-T & $\begin{array}{l}\text { Nof Antibiotics prescribed } \\
\mathbf{A C r}\end{array}$ & $\begin{array}{l}\mathbf{A C}-\mathbf{T} \\
\mathbf{+} \mathbf{T r}\end{array}$ & Total \\
\hline Cycle 1 & 7 & 5 & 7 & 19 \\
\hline Cycle 2 & 6 & 3 & 0 & 9 \\
\hline Cycle 3 & 2 & 4 & 1 & 7 \\
\hline Cycle 4 & 3 & 3 & 1 & 7 \\
\hline Cycle 5 & 6 & 2 & 5 & 13 \\
\hline Cycle 6 & 4 & 3 & 3 & 10 \\
\hline Cycle 7 & 1 & 1 & 2 & 4 \\
\hline Cycle 8 & 2 & 1 & 2 & 4 \\
\hline Total & 31 & 22 & 21 & 73 \\
\hline
\end{tabular}

Table 2: Comparison of number of days of ICU care in Cycle 1-8 in 3 regimens.

\begin{tabular}{|llllll|}
$\begin{array}{l}\text { No of } \\
\text { Cycles }\end{array}$ & AC-T & $\begin{array}{l}\text { AC- } \\
\text { T+Cr }\end{array}$ & $\begin{array}{l}\text { AC- } \\
\text { T+Tr }\end{array}$ & $\mathbf{Z}$ & $\begin{array}{l}\text { p } \\
\text { value }\end{array}$ \\
\hline Cycle 1 & $2.4 \pm 1.5$ & $3 \pm 0$ & $2.5 \pm 0.6$ & 2.68 & 0.261 \\
\hline Cycle 2 & $2.7 \pm 2.1$ & $2 \pm 1.4$ & $0 \pm 0$ & 0.09 & 0.767 \\
\hline Cycle 3 & $2 \pm 0$ & $3.5 \pm 3.5$ & $0 \pm 0$ & 0.1 & 1.00 \\
\hline Cycle 4 & $2 \pm 0$ & $3 \pm 0$ & $3 \pm 0$ & 3 & 0.223 \\
\hline Cycle 5 & $2.5 \pm 0.8$ & $3 \pm 0$ & $2.3 \pm 0.5$ & 2.34 & 0.310 \\
\hline Cycle 6 & $2 \pm 0$ & $2.7 \pm 1.2$ & $3 \pm 0$ & 2.4 & 0.301 \\
\hline Cycle 7 & $2 \pm 0$ & $0 \pm 0$ & $1 \pm 0$ & 1 & 0.317 \\
\hline Cycle 8 & $2.5 \pm 0.7$ & $3 \pm 0$ & $2 \pm 0$ & 1.5 & 0.472 \\
\hline Mean+ SD & & & & &
\end{tabular}

Longest number of days of ICU care was needed for regimen II patients during cycle 3 i.e.; $3.5 \pm 3.5$ days. No admission in the ICU was needed for regimen III patients during cycles 2 and 3. Similarly in regimen II during cycle 7 none of the patient required ICU admission.

\section{DISCUSSION}

Febrile neutropenia is the commonest cause for hospitalisation during/after chemotherapy in cancer patients. ${ }^{6}$ It is a life-threatening complication of cancer chemotherapy that needs treatment with appropriate antibiotics and granulocyte colony stimulating factor in intensive care units. Only those neutropenic episodes associated with at least one episode of fever more than onehour duration and count below 1000/dl, with expected rapid fall in count below $1000 / \mathrm{dl}$ or $500 / \mathrm{dl}$ in immediate period after chemotherapy come under febrile neutropenia. ${ }^{7}$

In present study, overall incidence of 61 episodes of febrile neutropenia $(6.1 \%)$ occurred. In Regimen I, 25 episodes $(2.5 \%)$, in regimen II 19 episodes $(1.9 \%)$ and in regimen III 17 episodes $(1.7 \%)$ were reported. There is no statistically significant difference among the 3 groups in the mean incidence of febrile neutropenia. According to a 
study conducted by Slamon D, et al febrile neutropenia was reported in $9.3 \%$ in AC-T group, $10.9 \%$ in AC-T+Tr group, $9.6 \%$ in $\mathrm{TCH}$ group. ${ }^{15}$

Early breast cancer is commonly treated with anthracyclines and taxanes. However, combining these drugs together increases the risk of myelotoxicity and requires granulocyte colony stimulating factor (G-CSF) support. In patients with early breast cancer at high risk for febrile neutropenia continued use of G-CSF prophylaxis during all chemotherapy cycles is of clinical relevance and thus cannot be abandoned. In a multicentric study by Aarts MJ et al on patients with breast cancer, 167 eligible patients are randomised into two groups, one group of 84 patients received G-CSF throughout all chemotherapy cycles (with taxanes and anthracyclines), eight (10\%) experienced an episode of febrile neutropenia and in the other arm with 83 patient who received G-CSF during only first two cycles, $30(36 \%)$ had experienced febrile neutropenia with a peak incidence of $24 \%$ in the third chemo cycle (i.e. first cycle without G-CSF prophylaxis). ${ }^{16}$ Prophylactic antibiotics and G-CSF have proven efficacy in preventing chemotherapy related febrile neutropenia. ${ }^{17,18}$ High risk breast cancer chemotherapy regimen includes the $\mathrm{AC}$ (Doxorubicin and Cyclophosphamide) followed by the Docetaxel, AC followed by Docetaxel and Carboplatin, AC followed by the Docetaxel and Trastuzumab. ${ }^{19}$ Adjuvant chemotherapy for patients with early-stage breast cancer has been shown to improve both disease-free survival and overall survival. ${ }^{20,21}$

According to EORTC guidelines for the use of granulocyte colony stimulating factor for chemotherapy induced febrile neutropenia in breast cancer in regimen AC-Docetaxel have a risk of 5-25\% (it is included in risk category $>20 \%$ ), so the guidelines recommend the use of G-CSF as mandatory for prophylaxis in this regimen. ${ }^{22}$ While $\mathrm{AC}$ alone regimen have a risk of 10-20\%, Docetaxel alone has a febrile neutropenia risk of $16-17 \% .{ }^{23}$ This result gives a correlation with this study that all 3 arms of study groups having AC in initial 4 cycles followed by either Docetaxel, or Docetaxel and Carboplatin, or Docetaxel and Trastuzumab in the following 4 cycles have high risk for incidence of febrile neutropenia. All patients received prophylactic support with G-CSF (either pegfilgrastim alone or with filgrastim during all cycles of chemotherapy). $73(58.9 \%)$ patients received only pegfilgrastim and $51(41.1 \%)$ received both pegfilgrastim and filgrastim either as prophylaxis or as treatment of established cases of febrile neutropenia. In a phase III study conducted by Vogel CL et al, in breast cancer patients taking Docetaxel, pegfilgrastim prophylaxis given group have an incidence of febrile neutropenia as $1 \%$ compared to placebo group which had $17 \%$ incidence. ${ }^{9}$

Those patients treated with filgrastim and oral antibiotics like Ciprofloxacin/ Amoxicillin-Clavulanic acid prophylacticaly have not developed febrile neutropenia. Febrile neutropenia needs immediate hospitalisation of patients with intravenous antibiotics and G-CSF for recovery of the neutrophil count to normal and prevention of sepsis related to low circulating neutrophils in peripheral blood. As a part of aggressive chemotherapy for breast cancer for better survival outcome and efficacy, authors have to continue the rest of the chemotherapy cycles after effectively treating the febrile neutropenia. Febrile neutropenia was treated with admission in intensive care unit and parenteral antibiotics. The antibiotics mainly used are the following ones like Piperacilline-Tazobactum, Meropenem, Ciprofloxacin, Amoxicilline-Clavulanic acid, Ceftriaxone etc. The antibiotics are continued for a period of 3-5 days even after discharge. Prophylactic use of oral antibiotics like Ciprofloxacin or Amoxicillin were given for prevention of the sepsis related to febrile neutropenia in susceptible patients or in those patients who have had at least one episode of febrile neutropenia previously. ${ }^{24} \mathrm{~A}$ study conducted by Minckwitz et al in breast cancer patients taking TAC (Docetaxel/ Adriamycin/ Cyclophosphamide) giving primary prophylaxis with Ciprofloxacin and pegfilgratim, pegfilgrastim alone, Ciprofloxacin alone, noticed that pegfilgrastim with Ciprofloxacin was more effective than daily G-CSF or Ciprofloxacin alone in preventing febrile neutropenia with a $\mathrm{p}$ value $<0.001 .^{25}$

Febrile neutropenia grade 4 with life threatening complications and high mortality rate needed immediate hospitalisation and intensive care support to prevent the neutropenic sepsis related complications. Among the 3 study groups, Carboplatin containg regimen II have more incidence of grade 4 febrile neutropenia $(14.7 \%)$ and more number of days of ICU care (up to 7 days) required in this group, as compared to regimen I with $9.8 \%$ and regimen III with $8.1 \%$. They are treated with G-CSF support either with pegfilgrastim or filgrastim or both and appropriate intravenous antibiotics were used according to the culture and sensitivity reports.

Grade 3 febrile neutropenia episodes are less severe than grade 4 and a total 41 episodes $(67 \%$ out of all febrile neutropenic episodes) occurred and needed ICU treatment for average of 2-3 days. Regimen I have more incidence of grade 3 febrile neutropenia than other two regimens. Only one patient required dose reduction due to febrile neutropenia and also the same patient had a delay in the next cycle of chemotherapy in regimen II.

Filgrastim / Pegfilgrastim support effectively reduced the incidence of febrile neutropenia similar to previous studies in the literature. The duration of treatment for established cases of febrile neutropenia in intensive care was for an average of 2-5 days and majority of the patients were treated with 3-5 antibiotics. No mortality was reported due to febrile neutropenia in this study during the study period.

\section{CONCLUSION}

Incidence of febrile neutropenia with high risk combination chemotherapy can be reduced with concurrent use of Filgrastim/ Pegfilgrastim. All patients who met with 
the episodes of febrile neutropenia were effectively treated with Filgrastim /Pegfilgrastim (G-CSF) and intravenous antibiotics in intensive care unit for an average of 2-5 days. No mortality was associated with febrile neutropenia in any of the regimens and all patients recovered effectively.

\section{Funding: No funding sources}

Conflict of interest: None declared

Ethical approval: The study was approved by the Institutional Ethics Committee

\section{REFERENCES}

1. Burstein HJ, Harris JR, Morrow Monica. Malignant tumors of the breast. In: Vincent T. Devitha, Hellman, Steven A Rosenberg; Cancer principles and practice of oncology, $9^{\text {th }}$ edition, Philadelphia, Wolters kluwer/Lippincott and Wilkins 2011;106:1401-44.

2. Hofstatter EW, Chung GG, Harris LN. Molecular biology of breast cancer. In: Vincent $\mathrm{T}$. Devitha, Hellman, Steven A Rosenberg; Cancer principles and practice of oncology, $9^{\text {th }}$ edition, Philadelphia, Wolters kluwer/Lippincott and Wilkins 2011;105:1392-1400.

3. Moulder S, Hortobagyi GN. Advances in the treatment of breast cancer. Clin Pharmacol Ther. 2008;83:26-36.

4. Chabner AB, Bertino J, Cleary J, Ortiz T, Lane A, Supko JG et al. Cytotoxic agents. In: Brunton LL, Chabner BA, Knollmann BC editors.Goodman and Gilman's the pharmacological Basis of therapeutics, $12^{\text {th }}$ edition, The McGraw hill companies new York 2011;61:1683-1715.

5. Wildiers H, Reiser M: Relative dose intensity of chemotherapy and its impact on outcome in patients with early breast cancer or aggressive lymphoma. Crit Rev Oncol Hematol. 2011;77:221-40.

6. Crawford J, Ozer H, Stoller R, Johnson D, Lyman G, Tabbara I, etal: Reduction by granulocyte colony stimulating factor for fever and neutropenia induced by chemotherapy in patients with small cell lung cancer. N Eng J Med.1991;325:164-170.

7. Aapro MS, Bohlius J, Cameron DA, Dal Lago L, Donnelly JP, Kearney N etal, European organisation of Research and Treatment of Cancer (2011) 2010 update of EORTC guidelines for the use of granulocyte colony stimulating factor to reduce the incidence of febrile neutropenia in adult patients with lymph proliferative disorders and solid tumours. Eur J Cancer. 2010;47:8-32.

8. Tew KD, Reed E, Saif WM, Chu E, Abu-Khalaf MM, Harris LN. Pharmacology of Cancer therapeutics /chemotherapeutic agents In: Vincent T.Devitha, Hellman, Steven A Rosenberg; Cancer principles and practice of oncology, $9^{\text {th }}$ edition, Philadelphia, Wolters kluwer/Lippincott and Wilkins. 2011;4(1):375-420.

9. Vogel CL, Wojtukiewicz MZ, Carroll RR, Tjulandin SA, Barajas Figueroa LJ, et al. First and subsequent cycle use of Pegfilgrastim prevents febrile neutropenia in patients with breast cancer: a multicenter, double blind, and placebo -controlled phase111 study. J Clin Oncol. 2005;23:1178-84.

10. Gea-Banacloche J, Segal BH. Infections in Cancer patients. In: Vincent T.Devitha, Hellman, Steven A Rosenberg; Cancer principles and practice of oncology, $9^{\text {th }}$ edition, Philadelphia, Wolters kluwer/Lippincott and Wilkins 2011;19(156):227298.

11. Chu E, Devitha VT. Physicians cancer chemotherapy drug manual, $1^{\text {st }}$ Indian edition, Wall Street Burlington, Jones and Bartett learning. 2013;442-49.

12. Canetta R, Rozencweig M, Carter SK. Carboplatin: The clinical spectrum to date. Cancer Treat Rev. 1985; 12(suppl A):125-36.

13. Van der Vijgh WJ. Clinical pharmacokinetics of Carboplatin. Clin Pharmacokinet. 1991; 21.

14. Aarts MJ, Peters FP, Mandigers CM, Dercksen MW, Stouthard JM, Nortier HJ, et al. Primary Granulocyte Colony stimulating factor prophylaxis during the first two cycles only or throughout all chemotherapy cycles in patients with breast cancer at risk for febrile neutropenia. J Clin Oncol. 2013;31:4290-6.

15. Slamon D, Eiermann W, Robert N, Pienkowski T, Martin M, Press M, et al. Adjuvant Trastuzumab in HER2-Positive Breast cancer. The N Eng J Med. 2011;365:1273-83.

16. Aarts MJ, Grutters JP, Peters FP, Mandigers CM, Dercksen MW, Stouthard JM, et al. Cost effectiveness of primary pegfilgrastim prophylaxis in patients with breast cancer at risk of febrile neutropenia. J Clin Oncol. 2013 Oct 28;31(34):4283-9.

17. Timmer-Bonte JN, de Boo TM, Smit HJ, Biesma B, Wilschut FA, Cheragwandi SA, Termeer A, et al. Prevention of chemotherapy-induced febrile neutropenia by prophylactic antibiotics plus or minus granulocyte colony-stimulating factor in small-cell lung cancer: a Dutch Randomized Phase III Study. J Clin Oncol. 2005 Nov 1;23(31):7974-84.

18. Cullen M, Baijal S: Prevention of febrile neutropenia: Use of prophylactic antibiotics. Br J Cancer. 2009 (suppl 1); 101:S11-S14.

19. Chabner AB, Bertino J, Cleary J, Ortiz T, Lane A, Supko JG, et al. Cytotoxic agents. In: Brunton LL, Chabner BA, Knollmann BC editors.Goodman and Gilman'S the pharmacological Basis of therapeutics, $12^{\text {th }}$ edition, The McGraw hill companies new York 2011;61:1683-1715.

20. Niederhuber JE, Armitage JO, Tepper JE, et al editors. Abeloff's clinical oncology, $5^{\text {th }}$ edition, Philadelphia, PA, Elsevier Saunders, 2014;29:434-484,91:16301691.

21. Nowak AK, Wilcken NR, Stockler MR, Hamilton A, Ghersi D. Systematic review of taxane-containing versus non-taxane-containing regimens for adjuvant and neoadjuvant treatment of early breast cancer. Lancet Oncol. 2004 Jun 1;5(6):372-80.

22. Aapro MS. European Organisation for Research and Treatment of Cancer (EORTC) Granulocyte ColonyStimulating Factor (GCSF) Guidelines Working Party: EORTC guidelines for the use of granulocyte- 
colony stimulating factor to reduce the incidence of chemotherapy-induced febrile neutropenia in adult patients with lymphomas and solid tumours. Eur J Cancer. 2006;42:2433-53.

23. Greil R, Psenak O, Roila F, ESMO guidelines working group: hematopoietic growth factors: ESMO recommendations for the applications. Ann Oncol. 2008;19(suppl 2):116-118.

24. Cullen M, Baijal S. Prevention of febrile neutropenia: Use of prophylactic antibiotics. Br J Cancer. 2009; (suppl 1); 101:S11-S14.

25. Von Minckwitz G, Kümmel S, Du Bois A, Eiermann W, Eidtmann H, Gerber B, et al. Pegfilgrastim \pm ciprofloxacin for primary prophylaxis with TAC (docetaxel/doxorubicin/cyclophosphamide) chemotherapy for breast cancer. Results from the GEPARTRIO study. Ann Oncol. 2007 Sep 9;19(2):292-8.

Cite this article as: Arun S, Mohamedali SP, Anuradha M. Pattern of management of febrile neutropenia among breast cancer patients treated with different chemotherapeutic regimens. Int J Basic Clin Pharmacol 2018;7:1829-36. 